\title{
A Novel In Vitro Model of Villitis of Unknown Etiology Demonstrates 1 Altered Placental Hormone and Cytokine Profile
}

Dol:

10.1111/aji.12725

\section{Document Version}

Accepted author manuscript

Link to publication record in Manchester Research Explorer

Citation for published version (APA):

Derricott, H., Heazell, A., Greenwood, S., \& Jones, R. (2017). A Novel In Vitro Model of Villitis of Unknown Etiology Demonstrates 1 Altered Placental Hormone and Cytokine Profile. American journal of reproductive immunology (New York, N.Y. : 1989). https://doi.org/10.1111/aji.12725

Published in:

American journal of reproductive immunology (New York, N.Y. : 1989)

\section{Citing this paper}

Please note that where the full-text provided on Manchester Research Explorer is the Author Accepted Manuscript or Proof version this may differ from the final Published version. If citing, it is advised that you check and use the publisher's definitive version.

\section{General rights}

Copyright and moral rights for the publications made accessible in the Research Explorer are retained by the authors and/or other copyright owners and it is a condition of accessing publications that users recognise and abide by the legal requirements associated with these rights.

\section{Takedown policy}

If you believe that this document breaches copyright please refer to the University of Manchester's Takedown Procedures [http://man.ac.uk/04Y6Bo] or contact uml.scholarlycommunications@manchester.ac.uk providing relevant details, so we can investigate your claim.

\section{OPEN ACCESS}




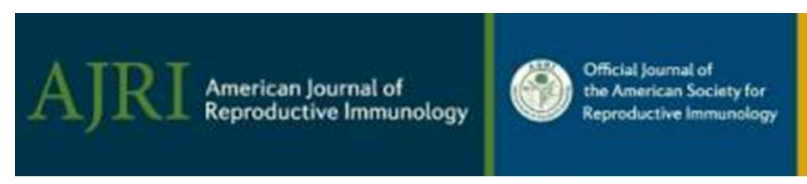

\section{A Novel In Vitro Model of Villitis of Unknown Etiology Demonstrates Altered Placental Hormone and Cytokine Profile}

\begin{tabular}{|r|l|}
\hline Journal: & American Journal of Reproductive Immunology \\
\hline Manuscript ID & AJRI-01-17-011.R1 \\
\hline Manuscript Type: & Technical Report \\
\hline Date Submitted by the Author: & 04-Apr-2017 \\
\hline Complete List of Authors: & $\begin{array}{l}\text { Derricott, Hayley; The University of Manchester, Maternal \& Fetal Health } \\
\text { Research Centre } \\
\text { Heazell, Alexander; University of Manchester, Maternal and Fetal Health } \\
\text { Research Centre } \\
\text { Greenwood, Susan; The University of Manchester, Maternal and Fetal } \\
\text { Health Research Centre } \\
\text { Jones, Rebecca; University of Manchester, Maternal and Fetal Health } \\
\text { Research Centre }\end{array}$ \\
\hline Keywords: & T cells, Placental dysfunction, Inflammation, VUE \\
\hline
\end{tabular}

SCHOLARONE ${ }^{m}$

Manuscripts 
1 A Novel In Vitro Model of Villitis of Unknown Etiology Demonstrates Altered Placental

2 Hormone and Cytokine Profile

3 Hayley Derricott PhD* Alexander E.P. Heazell MBChB PhD*, Susan L. Greenwood PhD*,

4 Rebecca L. Jones PhD*

5 *Maternal \& Fetal Health Research Centre, University of Manchester, Manchester Academic

6 Health Science Centre, Manchester M13 9WL

$7 \quad$ Running Title: Placental inflammation in vitro

8 Summary statement: Co-culture of human placental explants with matched maternal T-cells

9 elicits an inflammatory reaction that mimics villitis of unknown etiology and detrimentally 10 affects placental function.

11 Corresponding author: Hayley Derricott (hayley.derricott@liverpool.ac.uk)

12 Present address: Department of Infection Biology, Liverpool Science Park IC2, 146 Brownlow 13 Hill, Liverpool. L3 5RF 


\section{Abstract}

16 Problem: Placental dysfunction is present over $50 \%$ of cases of stillbirth and fetal growth 17 restriction (FGR). Villitis of unknown etiology (VUE), an inflammatory condition of the 18 placenta characterised by maternal T cell infiltrates in the villous stroma and dysregulation 19 of inflammatory cytokines, is more frequent in FGR and stillbirth.

20 Method of Study: A novel in vitro model of placental inflammation was developed to test 21 the hypothesis that inflammatory cells seen in VUE and/or cytokines impair placental 22 function.

23 Results: Co-culture of placental explants with maternal leukocytes resulted in increased 24 leukocytes in villous tissue and elevated concentrations of IL-1 $\beta$, IL-1Ra, IL-6, IL-10 and IFN- $\gamma$ 25 ( $p \leq 0.05)$. Human chorionic gonadotrophin secretion was reduced following co-culture with 26 leukocytes $(p \leq 0.01)$ and cytokines $(p \leq 0.05)$.

27 Conclusions: These observations support the hypothesis that altered placental inflammation 28 has deleterious effects on placental function. This model could be used to further 29 understanding about the pathophysiology of VUE and to test potential therapies.

30 Keywords: VUE, Inflammation, Placental dysfunction, T cells 
33 Placental dysfunction is cited as a cause of death in up to $65 \%$ of stillbirths (Flenady et al., 34 2011; Helgadóttir, 2012). Until recently, investigations of the origins of placental dysfunction 35 have generally concentrated on the implications of failure of spiral artery remodelling as 36 seen in early onset pre-eclampsia and fetal growth restriction (FGR) (Burton et al., 2009). 37 However, interest has grown in the consequences of placental inflammation and its contribution as a cause of stillbirth and FGR. Infectious agents such as cytomegalovirus or toxoplasmosis can lead to placental inflammation, though such cases are usually in the minority (Redline, 2007). More frequently, placental inflammation occurs in the absence of infection (Girard et al., 2014). Villitis of unknown etiology (VUE) is one such inflammatory condition of the villous tissue. As its name suggests, the origin of VUE is unknown, but it is not attributable to infectious agents.

VUE occurs in approximately $15 \%$ of term placentas, with a higher incidence in FGR (Derricott et al., 2013). Increased severity of inflammation has been linked to stillbirth (Redline, 2007) and it has been reported that VUE may recur in subsequent pregnancies (Redline and Abramowsky, 1985). VUE is characterised by infiltration of the placental villous stroma by maternal CD4 and CD8 T-cells (Kapur et al., 2004; Kim et al., 2008) and expansion of the placental macrophage (Hofbauer cell) population (Derricott et al., 2016; Kim et al., 2008, 2009; Redline and Patterson, 1993; Tang et al., 2011). The mechanisms by which this inflammatory infiltrate negatively affects placental function are unknown. We recently demonstrated altered cytokine protein levels in VUE lesions, including reduced interleukin (IL)-4 and elevated IL-2 and -12, indicating a localised pro-inflammatory environment in these placenta, which could disrupt normal placental viability and function (Derricott et al., 2016).

We hypothesised that the presence of maternal CD4 and CD8 T-cells and/or their related cytokines in the villous stroma damages trophoblast, the key functional cell layer, leading to impaired placental function. As VUE is diagnosed on histological examination of the placenta after delivery it cannot be detected before birth. This limits the ability to assess the effects of VUE on placental function using a traditional case-control or cohort study design. In the 
62 and CD8) were co-incubated with, and infiltrated, villous tissue explants from matched

placentas to assess the impact on placental function. We also utilised an established placental explant model to perturb specific cytokine levels, to reproduce the cytokine environment found in VUE in vivo (Abumaree et al., 2012; Audette et al., 2010; Benyo et al., 1997; Derricott et al., 2016; Heazell et al., 2008; Simán et al., 2001). In both cases a range of established placental analyses were used to assess the impact on trophoblast viability and placental function including: cell turnover, nutrient transport and endocrine function.

\section{$2 \quad$ Materials and Methods}

\subsection{Sample Collection}

Term (37-42 weeks) placentas $(n=14)$, with matched maternal blood samples $(n=8)$, were obtained within 30 minutes of delivery from women undergoing elective caesarean section. Tissue was donated with informed written consent in accordance with North West NHS REC approval (Ref: 08/H1010/55+5). Placental tissue was taken from uncomplicated pregnancies with the following exclusion criteria: maternal body mass index $\geq 30$, maternal disease (e.g. pre-eclampsia, hypertension, gestational diabetes mellitus), fetal anomalies, small for gestational age (SGA) infants (defined as individualised birthweight centile $(I B C)<10^{\text {th }}$ centile), or multiple pregnancies.

\subsection{Explant Culture with Cytokines}

Full thickness villous biopsies of $\sim 1 \mathrm{~cm}^{3}$ were randomly sampled from four different areas of placenta and dissected into $4-5 \mathrm{~mm}^{2}$ fragments. An established method of placental explant culture that has been extensively utilised to assess placental viability and function was employed (Audette et al., 2010; Lager and Powell, 2012; Simán et al., 2001). Explants were cultured for 4 days in CMRL-1066 culture medium (Gibco, Paisley, UK) supplemented with $5 \%$ heat-inactivated FBS, $100 \mathrm{IU} \mathrm{mL}^{-1}$ penicillin, $100 \mathrm{~g} \mathrm{~mL}^{-1}$ streptomycin, $1 \mu \mathrm{g} \mathrm{mL}^{-1}$ insulin, $0.1 \mu \mathrm{g} \mathrm{mL}{ }^{-1}$ hydrocortisone, and $0.1 \mathrm{\mu g} \mathrm{mL}^{-1}$ retinyl acetate (Sigma Aldrich, Dorset, UK). On day 4, explants were cultured in reduced serum Opti-MEM ${ }^{\circledast}$ medium (Gibco, Paisley, UK) and treated with recombinant human IL-2 (rhIL-2, $10 \mathrm{ng} \mathrm{mL}{ }^{-1}$ ), recombinant human IL-12 (rhIL-12, $10 \mathrm{ng} \mathrm{mL}^{-1}$ ) (Life Technologies, Paisley, UK) or IL-4 neutralising antibody $(1 \mu \mathrm{g} / \mathrm{mL}$, R\&D Systems, Oxford, UK) individually or all three in combination. Opti-MEM ${ }^{\circledR}$ alone served 
91 as the control. Conditioned culture medium was collected after 4 and 6 days of culture. On day 6 , explants were processed for analyses of placental viability, cell turnover, nutrient transport, endocrine section and cytokine expression.

\subsection{Placental Explant and Maternal T Cell Co-Culture}

95

Villous tissue explants were prepared as above. To enhance the accessibility of villous stroma to $\mathrm{T}$ cells, a mild trypsin treatment was carried out to lift areas of syncytiotrophoblast (STB), the endocrine/nutrient transporting epithelium that surrounds the villous stroma, without compromising tissue integrity and function.. Concentration of trypsin and incubation times were optimised by modifying a previously described treatment (Forbes et al., 2008) (see Derricott et al., 2015 for the full protocol). Following trypsinisation, explants were cultured for 24 hours in RPMI 1640 medium (Gibco, Paisley, Scotland) supplemented with $5 \%$ fetal bovine serum (FBS), $1 \mathrm{\mu g} \mathrm{mL}^{-1}$ insulin, $100 \mu \mathrm{g} \mathrm{m}^{-1}$ streptomycin sulphate, $100 \mathrm{IU} \mathrm{mL}^{-1}$ penicillin $\mathrm{G}, 0.1 \mu \mathrm{g} \mathrm{mL}^{-1}$ retinol acetate, $25 \mu \mathrm{g} \mathrm{mL}^{-1} \mathrm{~L}$-alanine, $200 \mu \mathrm{g}$ $\mathrm{mL}^{-1}$ L-cysteine and $50 \mu \mathrm{g} \mathrm{mL} \mathrm{m}^{-1}$ ascorbic acid. After $24 \mathrm{hrs}$, RPMl culture medium was aspirated and isolated CD4 and CD8 T-cells were applied to each explant in $10 \mu \mathrm{L}$ suspensions (approximately $10^{5}$ cells per explant). RPMI medium alone was applied to control tissue. After 24 hours, $300 \mu \mathrm{L}$ medium was added to each well, with a further media change after a further 24 hours. Conditioned medium was collected on days 3 and 4 . To ensure T cells remained viable for the duration of the culture, explants were harvested on day 4 and processed for analyses of placental function.

\subsection{CD4 and CD8 T Cell Isolation}

CD4 and CD8 T-cells were isolated from maternal blood samples with EasySep Human T Cell Isolation Kit (STEMCELL Technologies, Cambridge, UK) following the manufacturers' protocol. CD8 T cells were isolated from peripheral blood mononuclear cells (PBMCs) by positive selection, followed by negative selection of CD4 T cells. Isolated CD4 and CD8 T-cells were incubated for 24 hours on anti-CD3 (BD Pharmingen, Oxford, UK) coated 12-well plates in RPMI 1640 medium with $1 \mu \mathrm{g} \mathrm{m}^{-1}$ anti-CD28 antibody (BD Pharmingen) and $10 \mathrm{ng} \mathrm{mL}^{-1}$ recombinant IL-2 and IL-15 (Gibco, Paisley, UK) to activate and stimulate proliferation of T cells (Derricott et al., 2015). 


\section{$2.5 \quad$ CellTracker ${ }^{T M}$ Fluorescence}

121 Cultured CD4 and CD8 T-cells were harvested after 24 hours by application of ice-cold 122 Dulbecco's PBS (without $\mathrm{Ca}^{2+}$ and $\mathrm{Mg}^{2+}$ ) and gentle scraping. The manufacturer's protocol 123 for CellTracker ${ }^{\mathrm{TM}}$ fluorescence (Life Technologies, Paisley, UK) was followed to label CD4 T 124 cells red and CD8 T-cells green. Cell suspensions were re-suspended in RPMI supplemented with rhIL-2 and rhIL-15 before application to placental explants. Intracellular fluorescence was verified by viewing cells with a fluorescence microscope. Cell number and viability was assessed by counting using a haemocytometer and staining with Trypan Blue (Sigma Aldrich, 128 Poole, UK).

\subsection{Cell Migration}

130

\section{8}

\section{hCG and PIGF Hormone Secretion}

\subsection{Assessment of System A Amino Acid Transporter Activity}

Following the culture period, placental explants were incubated in buffer with the radiolabelled amino acid analogue $\mathrm{N}$-methylated aminoisobutyric acid $\left({ }^{14} \mathrm{C}\right.$-meAIB) at $0.5 \mu \mathrm{Ci}$ $\mathrm{mL}^{-1}(8.5 \mu \mathrm{M})$ as previously described (Audette et al., 2010). The incubation buffer was either control Tyrode's or $\mathrm{Na}^{+}$-free Tyrode's ( $\mathrm{NaCl}$ replaced with equimolar $\left(135 \mathrm{mM} \mathrm{L}^{-1}\right.$ ) choline chloride. Co-culture explants were incubated for 10, 30 or 60 minutes; explants cultured with cytokines were incubated for 60 minutes only. Following incubation, explants were lysed in $\mathrm{dH}_{2} \mathrm{O}$ then denatured in $0.3 \mathrm{M} \mathrm{NaOH}$ for assessment of protein content by Bio-Rad protein assay (Bio-Rad Laboratories, Hemel Hempstead, UK). The radioactivity of the explant lysate was determined using a $\beta$-scintillation counter. System $\mathrm{A}$ is a $\mathrm{Na}^{+}$-dependent nutrient transporter and its activity was calculated by subtracting ${ }^{14} \mathrm{C}$-meAlB uptake in $\mathrm{Na}^{+}$-free Tyrode's from uptake in control Tyrode's buffer, with adjustment for explant protein content. 
149 Conditioned culture medium was assayed for hCG and PIGF concentrations by ELISA (hCG: 150 DRG Diagnostics, Marburg, Germany, PIGF: Duoset ELISA, R\&D Systems, Oxford, UK) 151 according to the manufacturers' protocol. Plates were read on a FLUOstar Omega 152 microplate reader (BMG Labtech, Aylesbury, UK), values corrected for explant protein 153 content and expressed as $\mathrm{mIU} / \mathrm{mL} / \mathrm{mg}$ protein (hCG) or $\mathrm{pg} / \mathrm{mL} / \mathrm{mg}$ protein (PIGF).

\subsection{Proliferation, Apoptosis, STB Regeneration and Leukocytes in Explants}

Proliferation and apoptosis were assessed in formalin-fixed explants using immunostaining and quantification of markers of proliferation (Ki67; Dako, Cambridge, UK) and apoptosis (M30, Roche, West Sussex, UK). STB regeneration was investigated by assessing area of immunostaining for cytokeratin 7 (CK7, Dako). The presence of leukocytes in explants was determined by immunostaining for the cell surface marker CD45 (leukocyte common antigen, (Dako)). A standardised laboratory protocol for immunostaining with colorimetric detection was followed, as described previously ( Derricott et al., 2016; Hamilton et al., 2012). Primary antibodies were applied at the following concentrations: CK7 $0.9 \mu \mathrm{gL}^{-1}$, Ki67 $0.4 \mu \mathrm{g} \mathrm{mL} L^{-1}, \mathrm{M} 300.01 \mu \mathrm{g} \mathrm{mL} L^{-1}$, and CD45 $0.46 \mu \mathrm{gL}^{-1}$. Each tissue section had a corresponding negative control on which mouse IgG (Sigma Aldrich, Dorset, UK) was applied at the same concentration as the primary antibody.

\subsection{Image Capture and Analysis}

167

Explant sections were visualised using the $x 10$ objective of an Olympus BX41 light microscope (Southend-on-Sea, UK). Images were captured with Qlcam Fast 1394 camera (QImaging, BC, Canada) and Image Pro Plus 6.0 (Media Cybernetics Inc., MD, USA). Quantitative, unbiased quantification of staining area was completed using HistoQuest image analysis software (TissueGnostics, Vienna, Austria) (Chu et al., 2015; Derricott et al., 2016). Image pixels were converted to greyscale (0-256 scale) and assigned an arbitrary number following detection of DAB and haematoxylin and optimisation of staining intensity ranges. Results are presented as histograms or dot plot scattergrams to which staining area and/or intensity thresholds can be applied to differentiate between cell populations.

\subsection{Cytokine Analysis in Culture Supernatant and Tissue Lysates (Bio-Plex Assay)}


177 Tissue lysates were prepared using a Bio-Plex cell lysis kit (Bio-Rad Laboratories, Hemel 178 Hempstead, UK). Tissue culture medium and tissue lysates were analysed for a panel of 10 179 inflammation-related cytokines by Bio-Plex assay (Bio-Rad Laboratories, Hemel Hempstead, 180 UK) following manufacturers' instructions. The cytokines selected for assay were IL-1 $\beta$, IL181 1Ra, IL-2, IL-4, IL-6, IL-10, IL-12A (p70), IL-17, IFN- $\gamma$ and TNF- $\alpha$. Cytokine levels were 182 extrapolated from fluorescence values based on supplied standards.

\subsection{Statistical Analysis}

184

185

186

187

188

189

190

191

192

A power calculation using prior data on hCG secretion, system A activity and cytokine production and secretion from culture in hypoxic conditions or with dexamethasone determined that 4-6 samples per group would be required with an $80 \%$ power, $\alpha=0.05$ (Audette et al., 2010; Heazell et al., 2008). Statistical analyses were carried out using GraphPad Prism 6.0 software (San Diego, CA, USA). Non-parametric continuous data were analysed with Mann Whitney U-test or Kruskal-Wallis test with Dunn's post-hoc test. Comparisons between groups of non-parametric data were analysed using Wilcoxon signed rank test or Friedman test. Due to considerable variability in the basal values of control placentas, ELISA and immunohistochemistry results are presented as fold change from control.

\section{$3 \quad$ Results}

\subsection{An In Vitro Model of VUE Shows Altered Placental Function}

Representative images of the co-culture explants $(n=6)$ illustrate CD4 and CD8 T-cells in the intervillous space, the equivalent of the maternal blood space, and within the villous stroma (Figure 1). Flow cytometry demonstrated that positive (CD8) and negative (CD4) antibody selection techniques yielded T cell populations with $\sim 91 \%$ and $\sim 83 \%$ purity respectively. An average of $\sim 12,000$ cells (range $800-24,500$ ) was applied to each villous tissue fragment, with the T cell yield dependent on blood volume obtained. Isolated cells had an average viability of $97.9 \%$ (range 95.2-99.6\%). Immunohistochemistry for CD45 demonstrated a significant increase in leukocyte numbers in explants co-cultured with CD4/CD8 T-cells compared to controls ( $p \leq 0.05$; Figure $2 A$ ). Significant increases were detected in the concentrations of IL-1 $(p \leq 0.01)$, IL-10 ( $p \leq 0.05)$, IFN $p(p \leq 0.05)$ and IL-1Ra $(p \leq 0.05)$ secreted 
206 into culture medium from explants cultured with CD4/CD8 T-cells on day 3 . These 207 differences were diminished by day 4 of culture (data not shown). Significantly greater 208 concentrations of IL- $6(p \leq 0.01)$ and IL-1 $\beta(p \leq 0.05)$ were detected in the lysates of placental 209 explants cultured with T-cells compared to controls after 4 days of culture (Figure $2 F, G$ ). No 210 significant differences were detected in IL-2, $-4,-12,-17$ or TNF $\alpha$ in either culture 211 supernatant or tissue lysate samples.

212 There was a significant decrease in hCG concentrations in conditioned culture medium at 213 day 3 in the explants cultured with CD4/CD8 T-cells compared to those cultured in medium 214 alone ( $\leq \leq 0.01$; Figure 3A). A similar trend was detected for PIGF; however, in this group 215 there was a limited sample size ( $n=3$; Figure 3B). No significant differences were recorded in 216 hCG concentrations at day 4. There was no significant difference in system A activity of the 217 placental tissue or in proliferation, apoptosis or STB regeneration/area in the explants 218 cultured with CD4/CD8 T-cells compared to control (Figure 3D-F).

\section{$219 \quad 3.2 \quad$ Explant Culture with VUE-Associated Cytokines Alters Placental Function}

220 There was a significant decrease in human chorionic gonadotropin (hCG) concentrations in 221 conditioned culture medium at day 6 in the explants cultured with rhIL-2, rhIL-12 and IL-4 222 neutralising antibody in combination compared to control $(n=8, p<0.05)$ (Figure 4A). There 223 was a trend towards decreased placental growth factor (PIGF) in conditioned culture 224 medium at day 3 in the explants cultured with all treatments, but this did not reach 225 statistical significance ( $p=0.16$; Figure 1B). Treatment with individual cytokines did not affect 226 hCG production.

227 Placental system A activity was not significantly affected by independent or combined rhIL228 2, rhlL-12 and IL-4 neutralising antibody treatment compared to control (Figure 1C). A 229 significant reduction in proliferation (Ki67 staining) was detected in the explants treated 230 with IL-2 $(p<0.05)$. No significant differences were seen in apoptosis or STB 231 regeneration/area in any of the experimental conditions compared to control (Figure 1D-F).

232 No significant differences were observed in cytokine levels in explant lysates or conditioned 233 culture medium under any of the treatment conditions (Supplementary Figure 1).

2344 Discussion 
235 VUE is a well-documented inflammatory condition of the placenta in late pregnancy and its

236

237

238

239

240

241

242

243

244

245

246

247

248

249

250

251

252

253

254

255

256

257

258

259

260

261

262

263

264

265 association with poor pregnancy outcome (particularly FGR) is accepted (Aviram et al., 2010; Derricott et al., 2013; Vedmedovska et al., 2011). Despite these associations, little is known about the mechanisms by which VUE may cause placental insufficiency and adverse pregnancy outcome. Here we present new insights into the possible functional consequences of immune cell interaction with the placenta. This was possible due to the development of a novel in vitro model of placental inflammation involving co-culture of placental explants with matched T-cells obtained from maternal peripheral blood samples. We successfully introduced maternal immune cells into normal placental tissue and demonstrated induction of a localised pro-inflammatory response. Furthermore, both the presence of maternal immune cells within the villous core and treatment with VUEassociated cytokines detrimentally affect placental endocrine and/or syncytiotrophoblast function, as identified by the significant reduction in hCG secretion. As well as being a critical placental-derived hormone for the maintenance of pregnancy, hCG is a sensitive marker of syncytiotrophoblast renewal and viability (Evain-Brion and Malassine, 2003; Gude et al., 2004; Omata et al., 2013). These findings were supported by in vitro modulation of cytokine levels to mimic the altered cytokine profile detected in VUE lesions (Derricott et al., 2015). Deficiencies in hCG following inflammatory insult therefore indicate adverse effects on syncytiotrophoblast function or integrity. Consistent with this, hCG concentrations in maternal serum are reduced in pregnancy pathologies characterised by placental dysfunction, including intrauterine fetal demise and FGR (Dutton et al., 2012; Haddad et al., 1999; Londero et al., 2013). These findings support the hypothesis that VUE can adversely affect placental function, and provides a potential mechanistic link for the increasing susceptibility to FGR and/or stillbirth.

Increased expression and/or secretion of IL-1 $\beta$, IL-1RA, IL-6, IL-10 and IFN- $\gamma$ were detected from explants co-cultured with maternal T-cells. These data are consistent with our identification of IL-1 as a central mediator of inflammatory-induced placental dysfunction (Girard et al., 2014). Women reporting a reduction in fetal movements (RFM) have a 3-fold increased risk of stillbirth or FGR (Heazell and Frøen, 2008; Warrander et al., 2012); the placentas from these pregnancies exhibit marked syncytiotrophoblast dysfunction, including reduced nutrient transport capacity, accompanied by altered trophoblast proliferation and 
apoptosis, and impaired endocrine function, including a reduction in hCG (Dutton et al., 2012; Warrander et al., 2012). We recently identified elevated placental inflammation in these pregnancies, including increased expression of placental IL-1 family members, in the absence of infection (Girard et al., 2014). In trophoblast, as in other cell types, IL-1 potently stimulates the expression of other pro-inflammatory cytokines, e.g. IL-6 and CCL2, highlighting a coordinating role in mediating placental inflammation (Girard et al., 2015; Kandere-Grzybowska et al., 2003; Parikh et al., 1997). Furthermore, in vitro treatment with IL-1 impairs trophoblast fusion, viability, hCG secretion and system A activity (Girard et al., 2015). In the co-culture model in the current study, elevated concentrations of IL-1Ra were detected in the culture medium; this supports that the elevated IL-1 $\beta$ produced is functional, as IL-1Ra expression is stimulated as a consequence of IL-1R activation (Girard et al., 2014). These data, therefore, extend in vivo evidence of the contribution of placental inflammation to placental dysfunction and adverse pregnancy outcome.

Representative images of isolated T-cells in co-culture confirm that the cells were present in the intervillous space, and a proportion of T cells had migrated across the STB and infiltrated the placental villus. Chronic intervillositis of unknown etiology (CIUE), another inflammatory placental condition, describes the presence of lesions that are confined to the intervillous space (maternal blood space between placental villus structures) and comprise monocytes, CD4 and CD8 T cells of exclusively maternal origin (Capuani et al., 2013). Therefore, this in vitro model provides an overlapping model of VUE and CIUE and has functional relevance, as T-cells in the intervillous space and those in the villous stroma will have distinct interactions with placental cells. In CIUE, interactions will be between immune cells and the microvillous membrane of the syncytiotrophoblast, whereas in VUE immune cells within the villus core can interact with multiple cell types, including trophoblast, stromal cells and placental vasculature. The responses to these situations may vary depending on cell-cell interaction or cytokine receptor localisation on STB, stromal cells, endothelium, monocytes and macrophages. In VUE there is also the potential for interactions between maternal T-cells and fetal macrophages (Hofbauer cells). VUE has been likened to immune rejection; either the mother rejects the semiallogeneic placenta (host-versus-graft) (Redline, 2007; Rudzinski et al., 2013) or maternal T-cells infiltrate the placenta acting in a graft-versus-host manner (Hulthén Varli et al., 2012; Kim et al., 2006). What remains to be elucidated is the manner of 
297 maternal-fetal cell interaction. It is not yet known whether maternal T-cells can be activated

298 by fetal Hofbauer cells or whether they recognise fetal MHC as non-self.

299 It is perhaps unsurprising that exogenous treatment with VUE-associated cytokines did not 300 completely mirror those changes detected in the co-culture experiments. Culturing explants 301 with cytokines alone would not necessarily reflect a complex inflammatory phenomenon 302 such as VUE. Moreover, the physical presence of maternal immune cells within the placental 303 villus is likely to affect placental cell viability and function. It is highly likely that both the cell 304 and cytokine milieu is ultimately responsible for a cascade of events resulting in placental 305 dysfunction.

306 It should be noted that all of the placentas used in this study were from uncomplicated, 307 healthy pregnancies in which it is likely that maternal tolerance of the feto-placental unit 308 was well established. In addition, it was not possible to determine the Hofbauer cell 309 population in the placentas prior to culture, a factor which may influence maternal T cell 310 interactions in VUE (Kim et al., 2008). This may be a reason why experimental lesions were 311 not as extensive as those seen in the high grade villitis described in the literature (Redline, 312 2007; Russell, 1980). Other factors that may have influenced the extent of T cell infiltration 313 include the duration of the culture experiments compared to the duration of a pregnancy 314 and the lack of blood flow in the in vitro model. The study was limited by the length of time 315 the co-culture could be sustained. A culture period of 4 days was chosen in order that the 316 viability of the isolated T-cells could be maintained. The cytokine culture experiments could 317 be extended by using a cytotrophoblast culture model rather than an explant culture model, 318 although this would be more representative of the effect of generalised inflammation on 319 trophoblast rather than VUE on the placenta.

320 If chronic disruption of the syncytiotrophoblast had occurred, then a change in nutrient 321 transport capacity via system A may have been expected. The absence of a significant 322 alteration in system A activity is potentially related to the relatively short exposure to 323 cells/cytokines compared to that in utero. In this study, system A was chosen because of its 324 pivotal role in supporting fetal growth; placental system A activity is reduced in FGR 325 pregnancies compared to normal (Glazier et al., 1997) and in pregnancy associated with 
326 RFM (Warrander et al., 2012). However, there are multiple other nutrient transporter 327 systems present in the placenta that could have been affected.

328 This study provides the first evidence for functional consequences in the placenta of 329 inappropriate maternal immune responses, by the development and use of a novel in vitro 330 model of VUE. As VUE is a post-partum histopathological diagnosis, previous investigations 331 have been limited to descriptive studies, thus the scope for functional interpretation has 332 been limited. Furthermore, although VUE is reported to have an increased risk of 333 recurrence, there is no proposed treatment. The co-culture of placental villous tissue with 334 maternal T-cells demonstrates that the presence of maternal lymphocytes in the placenta, 335 and/or their derived cytokines, adversely affects placental function, which builds on 336 previous evidence highlighting that trophoblast fusion and syncytiotrophoblast renewal is 337 particularly susceptible to placental inflammation. Further use and development of in vitro 338 models of VUE and associated placental inflammation has the potential to determine the 339 mechanisms underlying associations between VUE and FGR and stillbirth, and to provide an 340 in vitro model to identify and test targets for therapeutic intervention. 
341 Acknowledgements:

342 We wish to express our gratitude to the mothers who donated their blood and gave consent 343 for us to use the placentas that we studied, the recruiters who consent the participants and 344 Dr Mark Wareing who co-ordinates the MFHRG Biobank. This work forms part of a PhD 345 project for HD funded by Tommy's - The Baby Charity.

346 Competing Interests:

347 No competing interests declared.

348 Author Contributions:

$349 \mathrm{HD}, \mathrm{RLJ}, \mathrm{SLG}$ and AEPH conceived and designed the experimental concept. HD and SLG 350 carried out the preliminary studies, HD carried out the experimental work. HD compiled the 351 manuscript, RLJ, SLG and AEPH provided editorial advice.

352 
353

354

355

356

357

358

359

360

361

362

363

364

365

366

367

368

369

370

371

372

373

374

375

376

377

378

379

380

381

\section{References}

Abumaree, M.H., Chamley, L.W., Badri, M., El-Muzaini, M.F., 2012. Trophoblast debris modulates the expression of immune proteins in macrophages: a key to maternal tolerance of the fetal allograft? J. Reprod. Immunol. 94, 131-41. doi:10.1016/j.jri.2012.03.488

Audette, M.C., Greenwood, S.L., Sibley, C.P., Jones, C.J.P., Challis, J.R.G., Matthews, S.G., Jones, R.L., 2010. Dexamethasone stimulates placental system A transport and trophoblast differentiation in term villous explants. Placenta 31, 97-105. doi:10.1016/j.placenta.2009.11.016

Aviram, R., Biron Shental, T., Kidron, D., 2010. Placental aetiologies of foetal growth restriction: clinical and pathological differences. Early Hum. Dev. 86, 59-63. doi:10.1016/j.earlhumdev.2010.01.020

Benyo, D.F., Miles, T.M., Conrad, K.P., 1997. Hypoxia stimulates cytokine production by villous explants from the human placenta. J. Clin. Endocrinol. Metab. 82, 1582-1588. doi:10.1210/jcem.82.5.3916

Burton, G.J., Charnock-Jones, D.S., Jauniaux, E., 2009. Regulation of vascular growth and function in the human placenta. Reproduction 138, 895-902. doi:10.1530/REP-09-0092

Capuani, C., Meggetto, F., Duga, I., Danjoux, M., March, M., Parant, O., Brousset, P., Aziza, J., 2013. Specific infiltration pattern of FOXP3+ regulatory T cells in chronic histiocytic intervillositis of unknown etiology. Placenta 34, 149-54. doi:10.1016/j.placenta.2012.12.004

Chu, Y.-T., Wan, S.-W., Anderson, R., Lin, Y.-S., 2015. Mast cell-macrophage dynamics in modulation of dengue virus infection in skin. Immunology 146, 163-172. doi:10.1111/imm.12492

Derricott, H., Jones, R.., Greenwood, S.., Batra, G., Evans, M.., Heazell, A.E.., 2016. Characterising Villitis of Unknown Etiology in Stillbirth. Am. J. Pathol. 186, 952-961. doi:10.1177/1933719114528275

Derricott, H., Jones, R., Heazell, A., Greenwood, S., 2015. Co-culture of placental explants with isolated CD4 and CD8 T cells: a functional model to define the consequences of 
382

383

384

385

386

387

388

389

390

391

392

393

394

395

396

397

398

399

400

401

402

403

404

405

406

407

408

409

410

placental inflammation. J. Biol. Methods 2, 1-10. doi:10.14440/jbm.2015.91

Derricott, H., Jones, R.L., Batra, G., Greenwood, S.L., 2015. Cell and Cytokine Profile of VUE Lesions in Stillbirth. Reprod. Sci. 22, 378A-379A.

Derricott, H., Jones, R.L., Greenwood, S.L., Batra, G., Evans, M.J., Heazell, A.E.P., 2016. Characterizing villitis of unknown etiology and inflammation in stillbirth. Am. J. Pathol. 186, 952-961. doi:10.1016/j.ajpath.2015.12.010

Derricott, H., Jones, R.L., Heazell, A.E.P., 2013. Investigating the association of villitis of unknown etiology with stillbirth and fetal growth restriction - a systematic review. Placenta 34, 856-62. doi:10.1016/j.placenta.2013.07.003

Dutton, P.J., Warrander, L.K., Roberts, S.A., Bernatavicius, G., Byrd, L.M., Gaze, D., Kroll, J., Jones, R.L., Sibley, C.P., Frøen, J.F., Heazell, A.E.P., 2012. Predictors of poor perinatal outcome following maternal perception of reduced fetal movements--a prospective cohort study. PLoS One 7, e39784. doi:10.1371/journal.pone.0039784

Evain-Brion, D., Malassine, A., 2003. Human placenta as an endocrine organ. Growth Horm. IGF Res. 13, 34-37. doi:10.1016/S1096-6374(03)00053-4

Flenady, V., Koopmans, L., Middleton, P., Frøen, J.F., Smith, G.C., Gibbons, K., Coory, M., Gordon, A., Ellwood, D., McIntyre, H.D., Fretts, R., Ezzati, M., 2011. Major risk factors for stillbirth in high-income countries: a systematic review and meta-analysis. Lancet 377, 1331-40. doi:10.1016/S0140-6736(10)62233-7

Forbes, K., Westwood, M., Baker, P.N., Aplin, J.D., 2008. Insulin-like growth factor I and II regulate the life cycle of trophoblast in the developing human placenta. Am. J. Physiol. 294, C1313-22. doi:10.1152/ajpcell.00035.2008

Girard, S., Heazell, A.E.P., Derricott, H., Allan, S.M., Sibley, C.P., Abrahams, V.M., Jones, R.L., 2014. Circulating Cytokines and Alarmins Associated with Placental Inflammation in High-Risk Pregnancies. Am. J. Reprod. Immunol. 72, 422-434. doi:10.1111/aji.12274

Girard, S., Jones, R.L., Guller, S., Sibley, C.P., Abrahams, V.M., 2015. Alarmins Potently Induce Inflammation in Placental Cells and Impair Trophoblast Turnover. Reprod. Sci. $22,108 \mathrm{~A}$.

Glazier, J.D., Cetin, I., Perugino, G., Ronzoni, S., Grey, A.M., Mahendran, D., Marconi, A.M., 

Pardi, G., Sibley, C.P., 1997. Association between the Activity of the System A Amino Acid Transporter in the Microvillous Plasma Membrane of the Human Placenta and Severity of Fetal Compromise in Intrauterine Growth Restriction. Pediatr. Res. 42, 514519.

Gude, N.M., Roberts, C.T., Kalionis, B., King, R.G., 2004. Growth and function of the normal human placenta. Thromb. Res. 114, 397-407. doi:10.1016/j.thromres.2004.06.038

Haddad, B., Abirached, F., Louis-Sylvestre, C., Le Blond, J., Paniel, B.J., Zorn, J.R., 1999. Predictive value of early human chorionic gonadotrophin serum profiles for fetal growth retardation. Hum. Reprod. 14, 2872-2875.

Hamilton, S., Oomomian, Y., Stephen, G., Shynlova, O., Tower, C.L., Garrod, A., Lye, S.J., Jones, R.L., 2012. Macrophages infiltrate the human and rat decidua during term and preterm labor: evidence that decidual inflammation precedes labor. Biol. Reprod. 86, 39. doi:10.1095/biolreprod.111.095505

Heazell, A.E.P., Frøen, J.F., 2008. Methods of fetal movement counting and the detection of fetal compromise. J. Obstet. Gynaecol. (Lahore). 28, 147-154.

Heazell, A.E.P., Lacey, H.A., Jones, C.J.P., Huppertz, B., Baker, P.N., Crocker, I.P., 2008. Effects of oxygen on cell turnover and expression of regulators of apoptosis in human placental trophoblast. Placenta 29, 175-86. doi:10.1016/j.placenta.2007.11.002

Helgadóttir, L.B., 2012. Intrauterine fetal death: classification and risk factors. A case-control study of sociodemographic, clinical and thrombophilic risk factors.

Hulthén Varli, I., Petersson, K., Kublickas, M., Papadogiannakis, N., 2012. Both acute and chronic placental inflammation are overrepresented in term stillbirths: a case-control study. Infect. Dis. Obstet. Gynecol. 2012, 1-8. doi:10.1155/2012/293867

Kandere-Grzybowska, K., Letourneau, R., Kempuraj, D., Donelan, J., Poplawski, S., Boucher, W., Athanassiou, A., Theoharides, T.C., 2003. IL-1 induces vesicular secretion of IL-6 without degranulation from human mast cells. J. Immunol. 171, 4830-4836. doi:10.4049/jimmunol.171.9.4830

Kapur, P., Rakheja, D., Gomez, A.M., Sheffield, J., Sanchez, P., Rogers, B.B., 2004. Characterization of inflammation in syphilitic villitis and in villitis of unknown etiology. Pediatr. Dev. Pathol. 7, 453-8; discussion 421. doi:10.1007/s10024-004-2124-3 
441 Kim, C.J., Kim, J.-S., Kim, Y.M., Mazaki-Tovi, S., Friel, L., Kusanovic, J.P., Espinoza, J., Hassan, 442 S., Romero, R., 2006. Villitis of unknown etiology: The pathophysiologic equivalent of 443 graft-versus-host disease in human pregnancy. Am. J. Obstet. Gynecol. 195, S90.

Kim, J.-S., Romero, R., Kim, M.R., Kim, Y.M., Friel, L., Espinoza, J., Kim, C.J., 2008. Involvement of Hofbauer cells and maternal T cells in villitis of unknown aetiology. Histopathology 52, 457-64. doi:10.1111/j.1365-2559.2008.02964.x

Kim, M.J., Romero, R., Kim, C.J., Tarca, A.L., Chhauy, S., LaJeunesse, C., Lee, D.-C., Draghici, S., Gotsch, F., Kusanovic, J.P., Hassan, S.S., Kim, J.-S., 2009. Villitis of unknown etiology is associated with a distinct pattern of chemokine up-regulation in the feto-maternal and placental compartments: implications for conjoint maternal allograft rejection and maternal anti-fetal graft-versus-host disease. J. Immunol. 182, 3919-27. doi:10.4049/jimmunol.0803834

Lager, S., Powell, T.L., 2012. Regulation of nutrient transport across the placenta. J. Pregnancy 2012, 1-14. doi:10.1155/2012/179827

Londero, A.P., Orsaria, M., Grassi, T., Calcagno, A., Marzinotto, S., Ceraudo, M., Fruscalzo, A., Driul, L., Mariuzzi, L., 2013. Placental hCG immunohistochemistry and serum free-BetahCG at 11-13 weeks' gestation in intrauterine fetal demise. Histochem. Cell Biol. 139, 595-603. doi:10.1007/s00418-012-1054-9

Omata, W., Ackerman, W.E., Vandre, D.D., Robinson, J.M., 2013. Trophoblast cell fusion and differentiation are mediated by both the protein kinase $\mathrm{C}$ and a pathways. PLoS One 8 , e81003. doi:10.1371/journal.pone.0081003

Parikh, A.A., Salzman, A.L., Kane, C.D., Fischer, J.E., Hasselgren, P.O., 1997. IL-6 production in human intestinal epithelial cells following stimulation with IL-1 beta is associated with activation of the transcription factor NF-kappa B. J. Surg. Res. 69, 139-144. doi:10.1006/jsre.1997.5061

Redline, R.W., 2007. Villitis of unknown etiology: noninfectious chronic villitis in the placenta. Hum. Pathol. 38, 1439-46. doi:10.1016/j.humpath.2007.05.025

Redline, R.W., Abramowsky, C.R., 1985. Clinical and pathologic aspects of recurrent placental villitis. Hum. Pathol. 16, 727-31. 
471 Redline, R.W., Patterson, P., 1993. Villitis of unknown etiology is associated with major 472 infiltration of fetal tissue by maternal inflammatory cells. Am. J. Pathol. 143, 473-9.

473 Rudzinski, E., Gilroy, M., Newbill, C., Morgan, T., 2013. Positive C4d immunostaining of 474 placental villous syncytiotrophoblasts supports host-versus-graft rejection in villitis of 475 unknown etiology. Pediatr. Dev. Pathol. 16, 7-13. doi:10.2350/12-05-1195-OA.1

476 Russell, P., 1980. Inflammatory lesions of the human placenta. III. The histopathology of 477 villitis of unknown aetiology. Placenta 1, 227-44.

478 Simán, C.M., Sibley, C.P., Jones, C.J., Turner, M.A., Greenwood, S.L., 2001. The functional 479 regeneration of syncytiotrophoblast in cultured explants of term placenta. Am. J. $480 \quad$ Physiol. 280, R1116-22.

481 Tang, Z., Abrahams, V.M., Mor, G., Guller, S., 2011. Placental Hofbauer cells and 482 complications of pregnancy. Ann. N. Y. Acad. Sci. 1221, 103-8. doi:10.1111/j.1749$483 \quad 6632.2010 .05932 . x$

Vedmedovska, N., Rezeberga, D., Teibe, U., Melderis, I., Donders, G.G.G., 2011. Placental 485 pathology in fetal growth restriction. Eur. J. Obstet. Gynecol. Reprod. Biol. 155, 36-40. doi:10.1016/j.ejogrb.2010.11.017

Warrander, L.K., Batra, G., Bernatavicius, G., Greenwood, S.L., Dutton, P., Jones, R.L., Sibley, C.P., Heazell, A.E.P., 2012. Maternal perception of reduced fetal movements is associated with altered placental structure and function. PLoS One 7, e34851. 490 doi:10.1371/journal.pone.0034851

491 


\begin{tabular}{|c|c|c|}
\hline & $\begin{array}{l}\text { Explant Co-Culture } \\
(n=8)\end{array}$ & $\begin{array}{l}\text { Explant Culture with } \\
\text { Cytokines }(n=6)\end{array}$ \\
\hline $\begin{array}{l}\text { Maternal Age } \\
\text { (years) }\end{array}$ & $36.5(34-45)$ & $32.5(26-38)$ \\
\hline $\begin{array}{l}\text { Gestational Age } \\
\text { (weeks }^{+ \text {days }} \text { ) }\end{array}$ & $39^{+1}\left(37^{+4}-39^{+2}\right)$ & $38^{+6}\left(38^{+0}-39^{+0}\right)$ \\
\hline $\begin{array}{l}\text { Maternal BMI } \\
\left(\mathrm{kg} / \mathrm{m}^{2}\right)\end{array}$ & $25.59(19.49-28.48)$ & $26.11(20.31-28.58)$ \\
\hline $\begin{array}{l}\text { Gravidity } \\
\text { (n) }\end{array}$ & $3(2-4)$ & $2(1-3)$ \\
\hline $\begin{array}{l}\text { Primiparity } \\
\text { (\%) }\end{array}$ & $62.5 \%$ & $67 \%$ \\
\hline $\begin{array}{l}\text { Birthweight } \\
\text { (grams) }\end{array}$ & $3450(2590-4000)$ & 3292.5 (2840-3630) \\
\hline IBC & $52.55(6.3-98.2)$ & $55.15(10.8-66.3)$ \\
\hline $\begin{array}{l}\text { Gender } \\
\% \text { male }\end{array}$ & $75 \%$ & $50 \%$ \\
\hline
\end{tabular}

Table 1: Demographic information of the study participants. Results are median (range). IBC - individialised birthweight centile, BMI - body mass index at time of booking to antenatal care. 

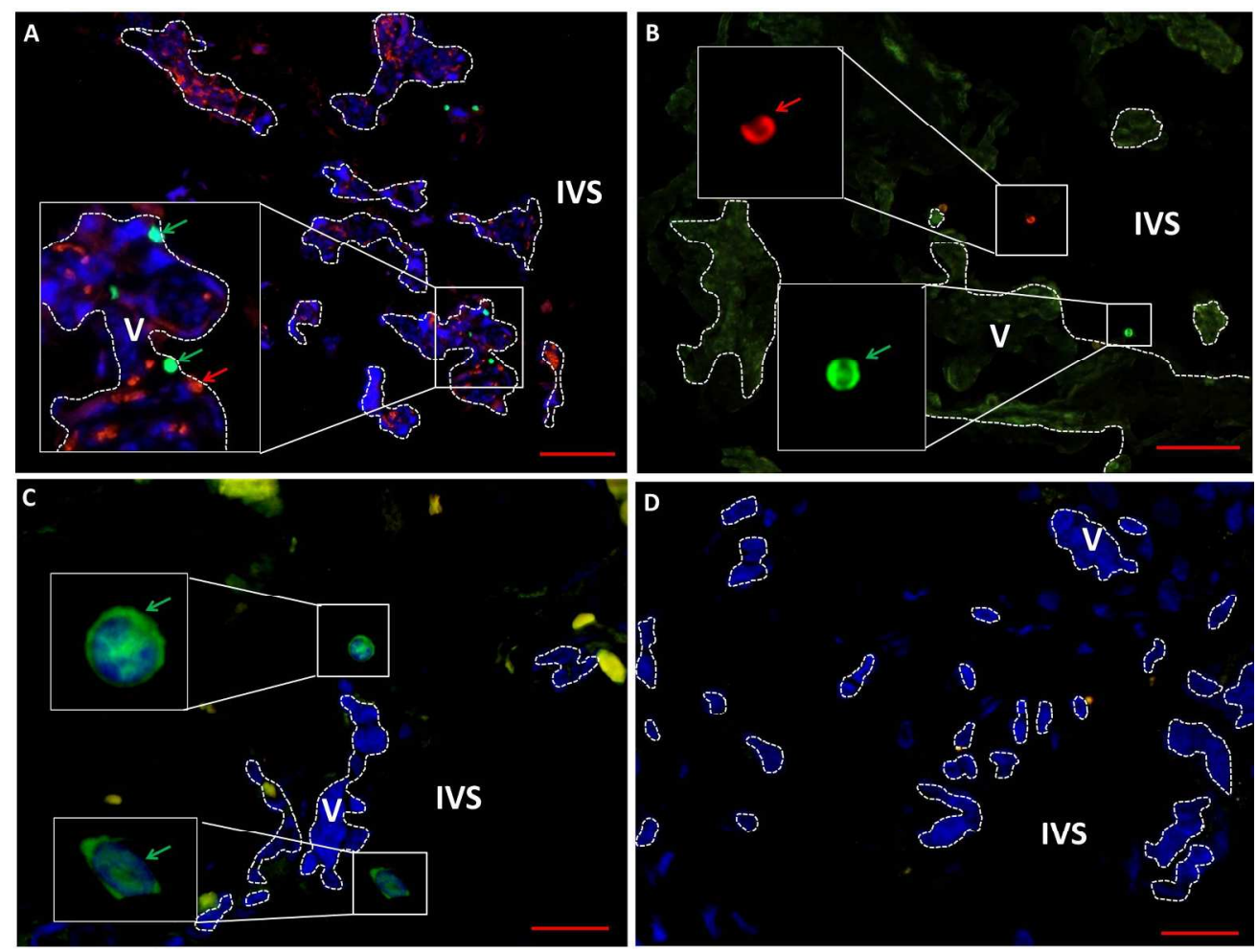

Figure 1: Representative images of explants at day 4 after culture with isolated T-cells. Red arrows highlight CD4 T-cells, green arrows highlight CD8 cells, A, C and D) nuclei stained blue with DAPI. A-C) Isolated maternal T-cells are visible in the villous stroma (V) and intervillous space (IVS). A-B) Scale bar represents $100 \mu \mathrm{m}$, original magnification $\times 200$, C) Scale bar represents $20 \mu \mathrm{m}$, original magnification x630 D) explant cultured without isolated cells, scale bar represents $20 \mu \mathrm{m}$, original magnification $\times 630$. Dotted lines delineate the perimeters of villi in cross-section where these can be accurately discerned. 

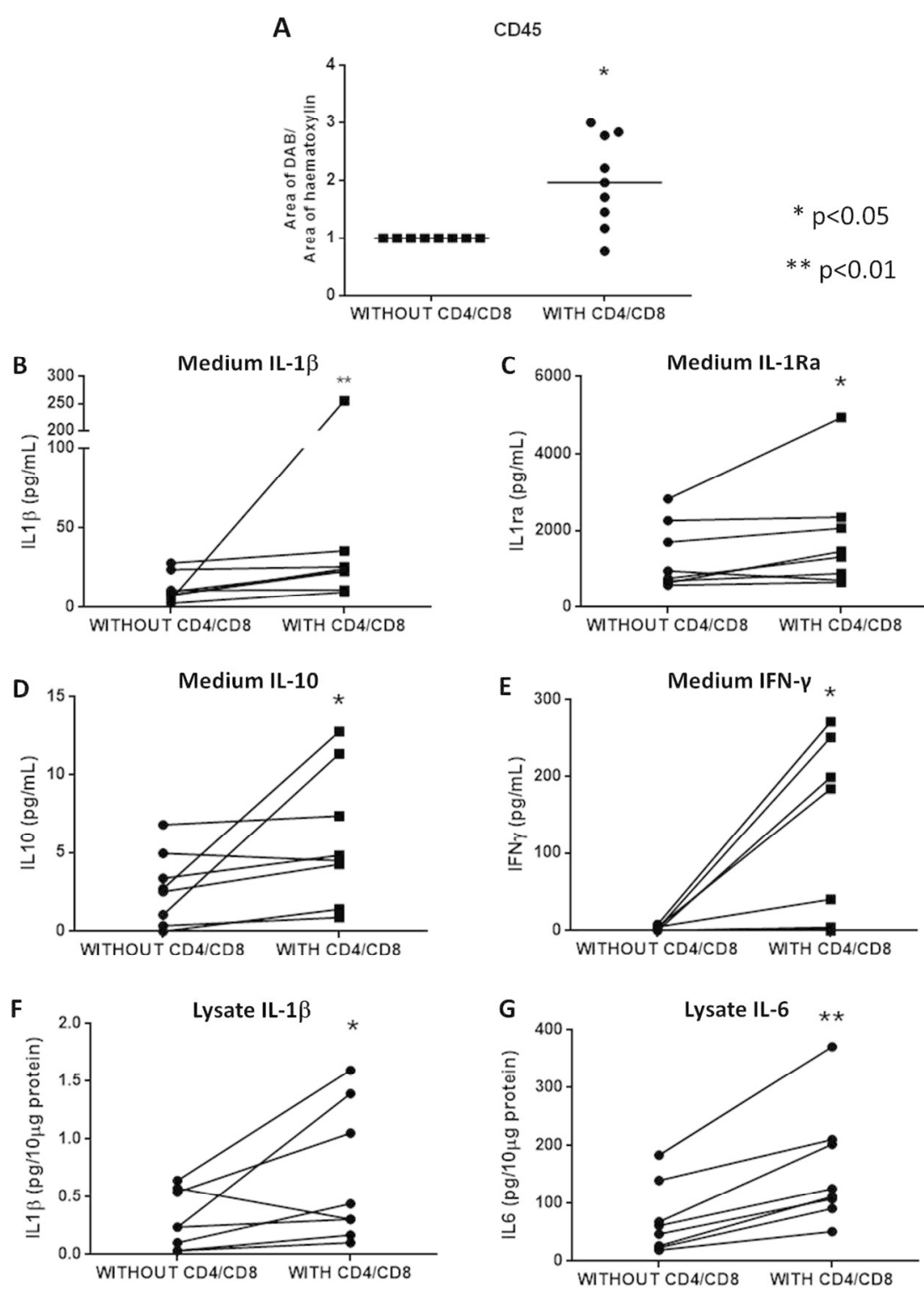

Figure 2: Effect of explant co-culture with matched maternal CD4 and CD8 T-cells on leukocyte number, cytokine release and tissue cytokines. (A) increased area of DAB+ staining for CD45 leukocytes presented as fold change compared to control $(p<0.05)$. Levels of IL-1 $\beta(B), I L-1 R a(C), I L 10(D)$ and IFNy (E) in culture medium were significantly elevated in the presence of CD4/CD8 T-cells compared to control. IL-1 $(F)$ and IL-6 (G) were significantly higher in the tissue lysates of explants co-cultured with T-cells compared to control. Wilcoxon signed rank test, $\mathrm{n}=8$.

\section{$231 \times 300 \mathrm{~mm}(150 \times 150 \mathrm{DPI})$}



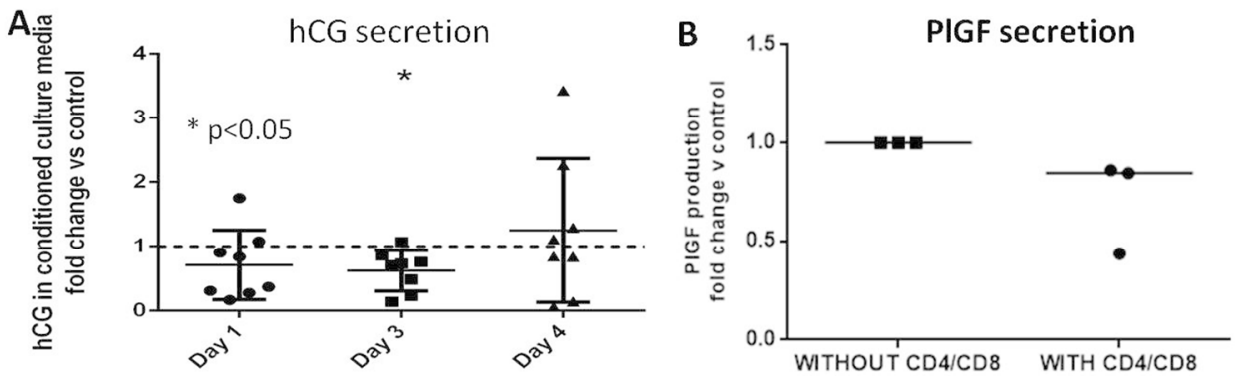

WITH CD4/CD8

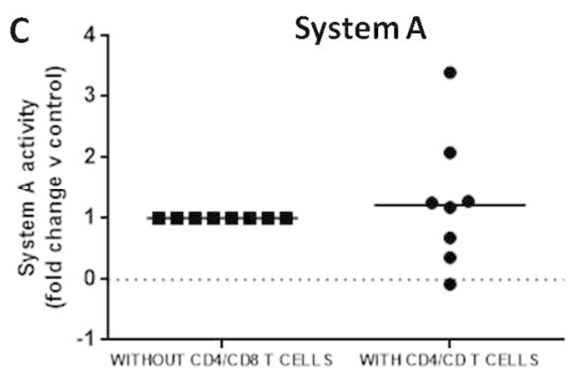

D

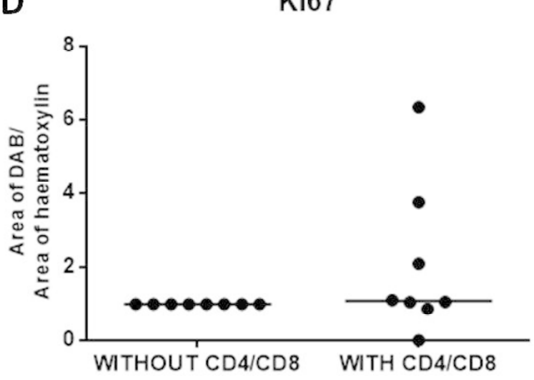

$E$

M30

F

CK7
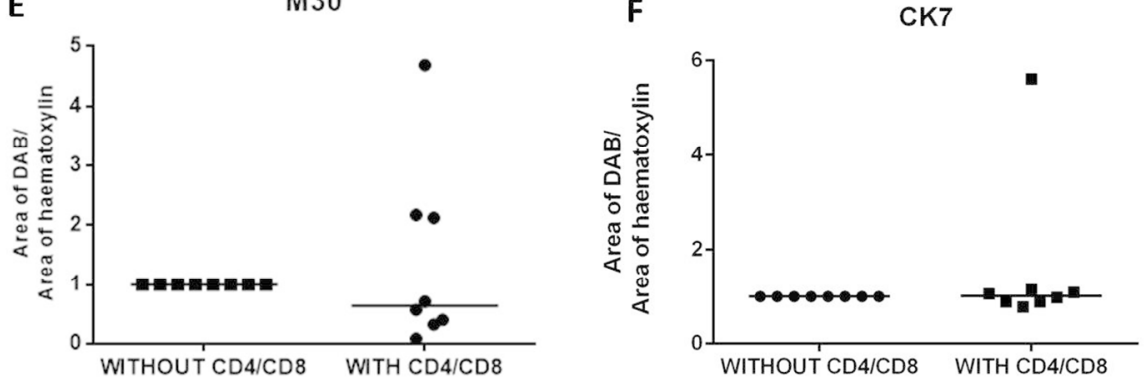

Figure 3: The effects of explant co-culture with matched maternal CD4 and CD8 T-cells on placental function and cell turnover. (A) hCG concentration in culture medium, (B) PIGF concentration in culture medium $(n=3),(C)$ system A activity (amino acid transporter). DAB+ staining area presented as fold change compared to control of (D) Ki67 (proliferation), (E) M30 (apoptosis) and (F) cytokeratin 7 (syncytiotrophoblast). Lines represent median. ( $A, C-E)$ Wilcoxon signed rank test, $n=8$ (B) no statistical analysis performed, $\mathrm{n}=3$.

$$
234 \times 235 \mathrm{~mm}(150 \times 150 \mathrm{DPI})
$$


A

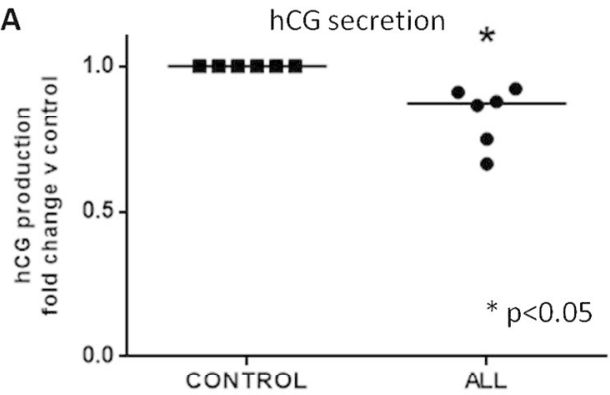

C

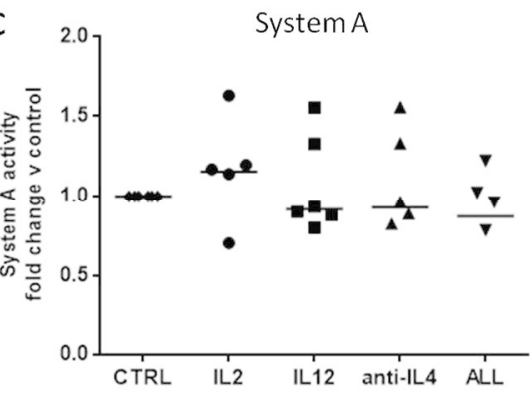

E

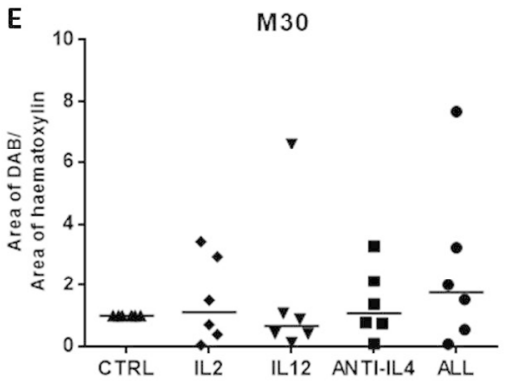

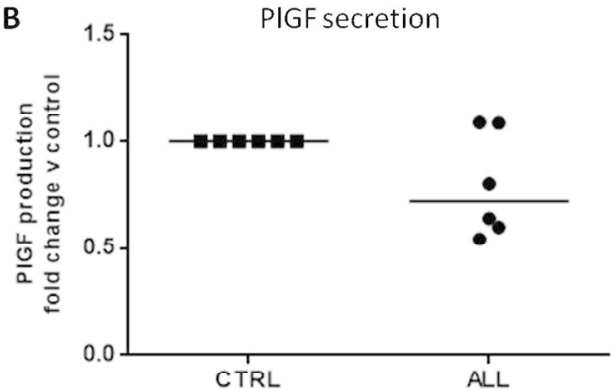

D

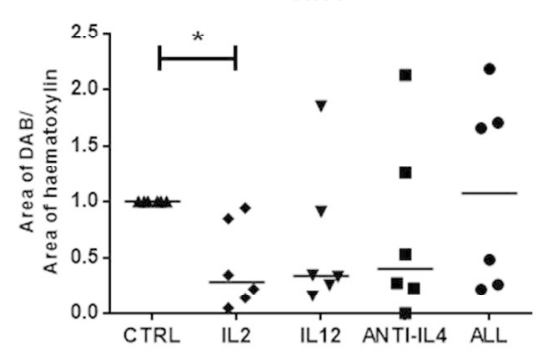

F

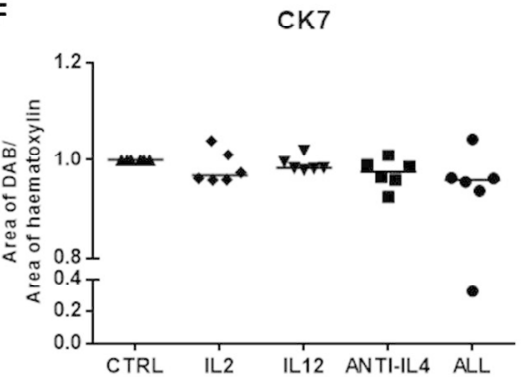

Figure 4: The effects of placental explant culture with cytokines and/or neutralising antibodies. (A) hCG concentration in culture medium, (B) PIGF concentration in culture medium, (C) System A activity (amino acid transporter). DAB+ staining area presented as fold change from control: (D) Ki67 (proliferation), (E) M30 (apoptosis) and (F) cytokeratin 7 (syncytiotrophoblast). CTRL: no treatment, IL-2: treatment with $10 \mathrm{ng} / \mathrm{mL}$ rhIL-2, IL-12: treatment with $10 \mathrm{ng} / \mathrm{mL}$ rhIL-12, ANTI-IL4: treatment with $1 \mathrm{mg} / \mathrm{mL}$ anti-IL4 neutralising antibody, ALL: treatment with $10 \mathrm{ng} / \mathrm{mL} \mathrm{IL-2,} \mathrm{IL-12} \mathrm{and} 1 \mathrm{mg} / \mathrm{mL}$ anti-IL4. Lines represent median. (A-B, D-F) Wilcoxon signed rank test, (C) Kruskal-Wallis test, $n=6$.

$267 \times 265 \mathrm{~mm}(150 \times 150 \mathrm{DPI})$ 

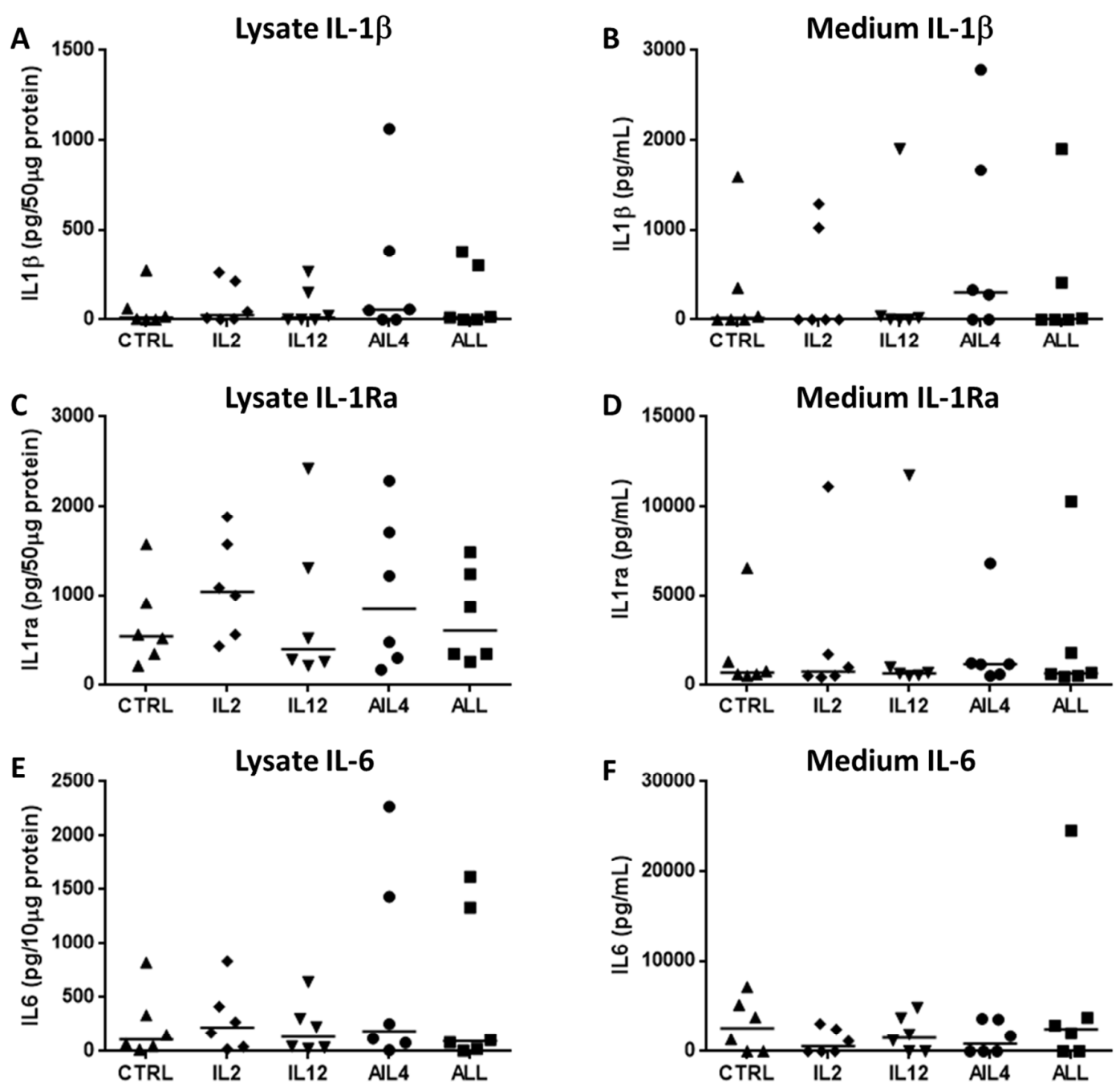